\title{
Role of dynamic strain ageing in low cycle fatigue
}

\author{
S L MANNAN \\ Materials Development Division, Indira Gandhi Centre for Atomic Research, Kalpakkam \\ 603102 , India
}

\begin{abstract}
Low cycle fatigue (LCF) at elevated temperatures is known to be influenced by time-dependent processes like creep, oxidation and metallurgical instabilities. Another timedependent phenomenon namely, dynamic strain ageing (DSA) has been found to exert an influence on LCF behaviour at high temperatures. Research activities carried out in the present author's laboratory with a view to understanding the effects of DSA on LCF are highlighted in this paper. Occurrence of DSA manifests during total strain-controlled fatigue tests in the form of serrated plastic flow in stress-strain hysteresis loops, increased cyclic work hardening and reduced plastic strain range. Further, DSA causes localization of plastic flow leading to enhanced planarity of slip and widely-spaced slip bands. Impingement of slip bands on grain boundaries causes increased grain boundary decohesion, leading to reduced fatigue life. The influence of prior microstructure such as second phase particles and grain size on the effects of DSA on LCF is also discussed.
\end{abstract}

Keywords. Dynamic strain ageing; low cycle fatigue; serrated plastic flow; slip band impingement; grain boundary decohesion; grain size dependence.

\section{Introduction}

Low cycle fatigue (LCF) is an important design consideration in structural integrity analysis of components operating at high temperatures. Repeated thermal stresses are generated as a result of temperature gradients which occur on heating and cooling during start-up, shut-down and thermal transient conditions. LCF resulting from startups and shut-downs occurs under essentially strain-controlled conditions, since the surface region is constrained by the bulk of the component. At elevated temperatures, LCF behaviour of structural materials is a complex phenomenon. It is generally observed that fatigue life decreases with (i) increase in test temperature and (ii) decrease in cyclic frequency or strain rate. In other words, the observed changes in fatigue behaviour at high temperatures are due to the interaction of cyclic deformation with one or more of the thermally-activated and time-dependent processes such as creep, oxidation, dynamic strain ageing (DSA), slip mode change and microstructural instability. As a consequence, various test parameters like frequency (strain rate), waveform, hold position, hold duration and strain range are found to exert strong influence on LCF life at elevated temperatures (Coffin 1974, 1977; Pineau 1983; Bressers 1985).

Extensive studies have been carried out in the author's laboratory to ascertain the interactive influence of creep and environment on LCF properties at elevated temperatures (Bhanu Sankara Rao et al 1986b, 1993; Sandhya et al 1989; Valsan et al 1989; Choudhary et al 1991). These studies, by and large, indicate that these two time-dependent mechanisms contribute significantly to the loss of LCF life under tensile hold or slow strain rate $\left(\dot{\varepsilon}=2 \times \Delta \varepsilon_{t} \times v\right)$ conditions. The degradation in life has been observed (Yamaguchi et al 1977; Hirakawa et al 1978) also under test conditions 
where creep and oxidation effects are expected to be minimal. It is shown that another time-dependent process namely, dynamic strain ageing interacts with fatigue and leads to life reduction. Austenitic stainless steels and superalloys have been found to exhibit DSA under test conditions which encompass service conditions. The understanding of the influence of DSA on both monotonic and cyclic properties of these materials used for high temperature service is therefore of great technological importance. Austenitic stainless steels (type AISI 304, type AISI 316) have been chosen worldwide for structural and core components of liquid metal-cooled fast breeder reactors (LMFBRs). These components operate in the temperature range (673-973 K) in which DSA is known to occur. Alloy Nimonic PE16 is an important candidate material for in-core components of the reactor because of its excellent resistance to void swelling. The phenomenon of DSA during monotonic deformation of these materials has been well understood (Mannan 1981; Mannan et al 1983; Bhanu Sankara Rao et al 1986a; Samuel et al 1988; Venkadesan et al 1992), but little is known about the influence of DSA on LCF deformation and fracture of these materials. In order to understand the role of DSA in LCF, a series of high temperature LCF studies have been carried out in our laboratory in austenitic stainless steels (type 304, type 316) (Bhanu Sankara Rao 1989; Bhanu Sankara Rao et al 1986b, 1986c, 1990, 1991; Srinivasan et al 1991) and alloy PE16 (Valsan et al 1993). A brief summary of high temperature LCF is first given, followed by some fundamentals of DSA. A detailed account of work carried out in author's group relating to the role of DSA in LCF is then presented.

\section{High temperature low cycle fatigue}

LCF behaviour of materials at high temperatures and low test frequencies is influenced due to the interaction of time-dependent processes like creep, oxidation, DSA and metallurgical instabilities with cyclic deformation. In general, the fatigue life decreases with increasing temperature and lowering of frequency. A few exceptions, however, have been reported as in the case of type 304 SS (Bhanu Sankara Rao 1989), type 316 SS (Kanazawa and Yoshida 1974) and 12\% Cr ferritic steel (Kanazawa 1978). In the case of type 304 SS (Bhanu Sankara Rao 1989), the observed increase in fatigue life with temperature correlated with the precipitation of $\mathbf{M}_{23} \mathbf{C}_{6}$ carbides during testing. This carbide precipitation along grain boundaries inhibits grain boundary sliding, thereby preventing grain boundary crack formation. Since LCF life at elevated temperature is governed by intergranular crack initiation and propagation, reduced tendency for grain boundary cracking due to precipitation led to enhanced life with increasing temperature (Bhanu Sankara Rao 1989).

Elevated temperature fatigue tests conducted in air generally yield lower life than those carried out in vacuum, suggesting the deleterious effects of oxidation on fatigue properties (Coffin 1972; Solomon and Coffin 1973; Cook and Skelton 1979). High temperature low cycle fatigue (HTLCF) studies in ferritic steels such as $2 \cdot 25 \mathrm{Cr}-1 \mathrm{Mo}$ (Sandhya et al 1989), 9Cr-1Mo (Choudhary et al 1991) indicate that oxidation enhances the intergranular damage and consequently causes reduction in life. The effect of oxidation was more dominant in tests conducted at low strain amplitudes. This is due to the fact that crack initiation is the dominant stage governing the life at low strain ranges. Crack initiation is enhanced due to environmental attack of 
surface grain boundaries leading to reduced life at low strain ranges. Fatigue-oxidation interaction has also been observed to degrade the life in austenitic stainless steels (Bhanu Sankara Rao et al 1986b). Creep-fatigue interaction in type 304 SS has been studied by performing hold time tests (Bhanu Sankara Rao 1989). The results of this study indicate that tensile hold caused more damage to life than either compression hold or symmetrical (tension + compression) hold. Under tensile hold condition, the accumulation of intergranular creep damage in the form of cavities enhanced the tendency for intergranular mode of fatigue crack propagation leading to shorter fatigue life.

With decrease in the strain amplitude of cycling, the interaction of creep or oxidation with LCF becomes more pronounced causing life reduction much lower than that predicted from high strain amplitude resulting in two slope behaviour (Coffin 1971; Sanders and Starke 1977; Clavel et al 1980; Mediratta et al 1986). This trend was observed in $2 \cdot 25 \mathrm{Cr}-1 \mathrm{Mo}$ steel when fatigue-tested at $773 \mathrm{~K}$ (Sandhya et al 1989). Two slope behaviour in strain-life plots was also observed in the case of Nimonic PE16 superalloy in peak aged condition (Valsan et al 1989). A change in deformation mode from homogeneous slip at high strain amplitudes to the formation of planar slip bands at low strain amplitudes in this case, led to the two-slope behaviour in strain-life plots. Impingement of slip bands on grain boundaries caused intergranular cracking, resulting in reduced life.

\section{Dynamic strain ageing}

Dynamic strain ageing (DSA) arises due to interactions between solute atoms and mobile dislocations during plastic deformation. It is also referred to as Portevin-Le Chatelier effect. Important manifestations of this phenomenon are the repeated appearance of serrations, load drops, jerkiness or other discontinuities in the stressstrain curves obtained in constant extension rate tensile or compressive tests. In constant loading rate tests and in creep tests under constant load or stress, DSA manifests itself as sudden bursts of plastic strain occurring periodically giving the curves the shape of a staircase.

The serrations are broadly classified based on their shape and termed as A, B, C, $D$ and $E$ (figure 1). The characteristics of the different types of serrations and the experimental conditions that produce them have been discussed in detail in a review by Rodriguez (1984). For the onset of serrations, a critical strain, $\varepsilon_{c}$ is generally required. At high strain rates and low temperatures, $\varepsilon_{c}$ increases with increasing $\dot{\varepsilon}$ and decreasing temperature. At low strain rates and high temperatures, $\varepsilon_{c}$ increases with decreasing $\dot{\varepsilon}$ and increasing temperatures. Various models have been proposed (Cottrell 1953; Sleeswyk 1958; McCormick 1972; Mulford and Kocks 1979; Van den Beukel and Kocks 1982; Hayes and Hayes 1984; Kubin and Estrin 1990) to account for the existence of critical strain for serrations and for appearance and disappearance of serrations from the flow curves. The presence of precipitates has been shown to have important influence on the strain for appearance and disappearance of serrations (Hayes and Hayes 1984).

In addition to the observation of serrations, other manifestations (figure 2) of DSA during monotonic deformation include (i) minimum in strain rate sensitivity $(\Delta \sigma / \Delta \ln \dot{\varepsilon})$, where $\Delta \sigma$ is the change in flow stress due to change in strain rate $(\dot{\varepsilon})$. This para- 


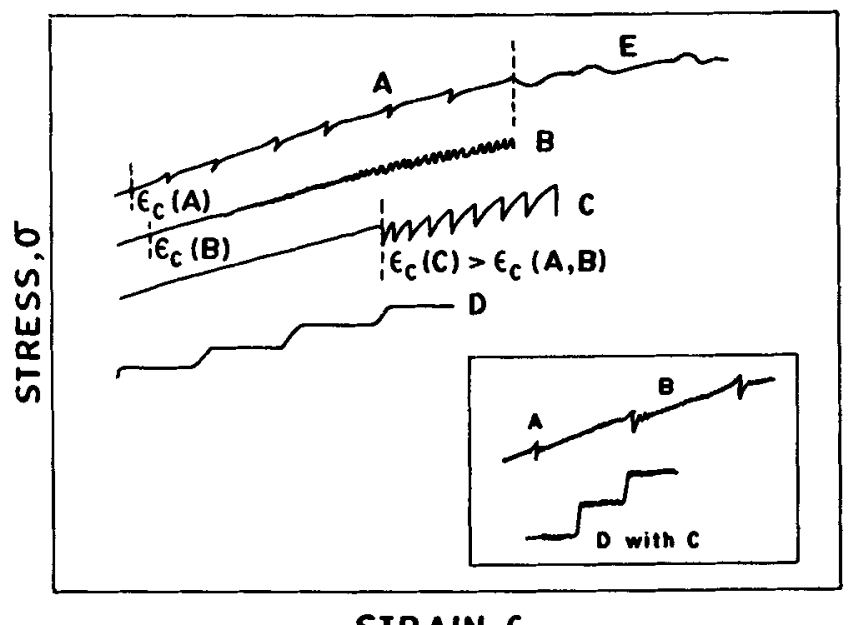

SIRAIN, $E$

Figure 1. Types of serrations.

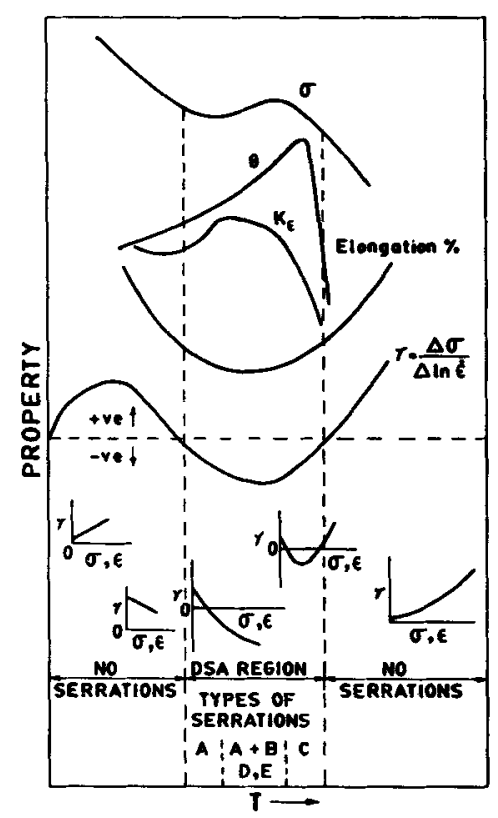

Figure 2. Schematic illustration of the various manifestations of dynamic strain ageing.

meter is negative in the temperature region of serrated flow, (ii) peak in flow stress, work hardening rate $(\theta=\delta \sigma / \delta \varepsilon)$ and Hall-Petch slope $K_{\varepsilon}$ with temperature $(T)$ and (iii) minimum in variation of ductility with $T$.

The phenomenon of DSA in an austenitic stainless steel (Mannan 1981; Mannan et al 1982, 1983; Samuel et al 1988) and alloy PE16 (Bhanu Sankara Rao et al 1986a) has been investigated in detail under monotonic tensile loading conditions. Prior metallurgical condition of type 316 SS has been shown to influence DSA very signi- 


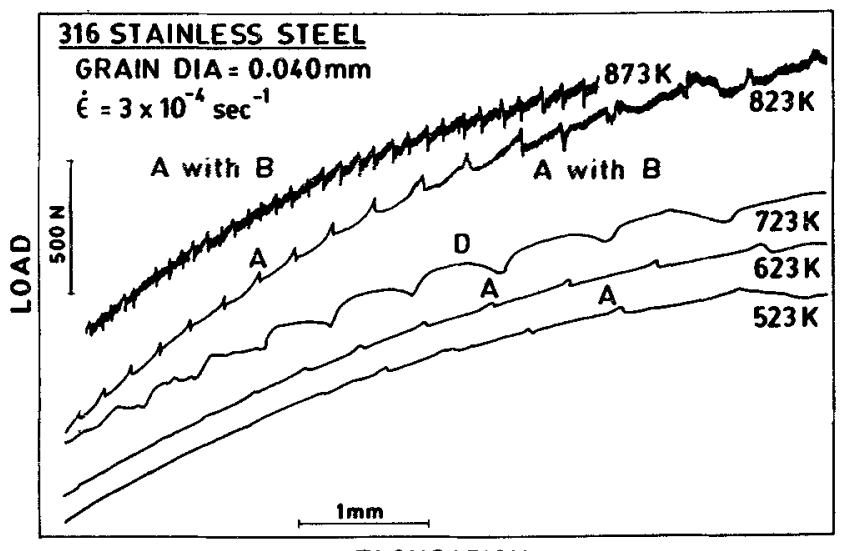

ELONGATION

Figure 3. Serrated plastic flow in 316 stainless steel with grain size $d=0.04 \mathrm{~mm}$.

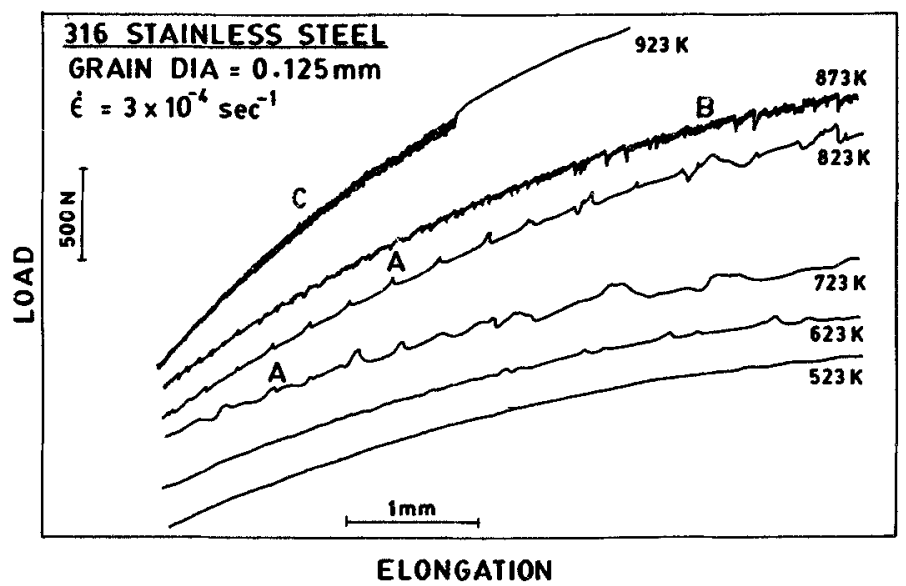

Figure 4. Serrated plastic flow in 316 stainless steel with grain size $d=0 \cdot 125 \mathrm{~mm}$.

ficantly in addition to test parameters like strain rate and temperature. The type of serrations was found to depend on strain rate, temperature and grain size (figures 3 and 4). The magnitude of stress drops increased with decreasing grain size. Critical strain for the onset of serrated flow was found to increase with grain size and this dependence has been attributed to the grain size dependence of dislocation density (Mannan 1981; Mannan et al 1983). Two temperature regions with different activation energies have been identified for serrated flow (Samuel et al 1988). The mechanism of serrated flow in low temperature region $(523-623 \mathrm{~K})$ is the diffusion of interstitial solutes to dislocations, while substitutional solutes like $\mathrm{Cr}$ are responsible for serrated flow in high temperature region $(673-923 \mathrm{~K})$. Further in a study of the effect of ageing in the temperature range ( $823-1323 \mathrm{~K}$ ) on serrated flow, it has been shown that certain time-temperature combinations of ageing eliminate serrated yielding, suggesting the important role of grain boundaries as preferred sites for dynamic strain ageing. In the case of alloy PE16 in the double aged condition, serrated flow was found to occur 
in the temperature range 523 to $873 \mathrm{~K}$ and at strain rates lower than $3 \times 10^{-3} \mathrm{~s}^{-1}$ (Bhanu Sankara Rao et al 1986a). It was attributed to the interaction of substitutional solutes with dislocations. In the following sections, work carried out in author's laboratory to understand the role of DSA in determining low cycle fatigue deformation and fracture behaviour is discussed.

\section{DSA during low cycle fatigue}

The role of DSA in LCF could be assessed by performing tests with varying strain rates at constant temperature and/or varying temperatures at constant strain rate. First, various manifestations of DSA during LCF would be discussed. This would be followed by a discussion of the influence of DSA on LCF deformation and fracture in austenitic stainless steel and Nimonic PE16. In the light of these effects, the degradation that occurs in LCF life would then be considered. Finally the influence of microstructural parameters like grain size in austenitic stainless steel on occurrence of DSA and its impact on LCF deformation and fracture would be highlighted.

DSA manifests during cyclic deformation in the form of serrations in stress-strain hysteresis loops as shown in figure 5 (Bhanu Sankara Rao et al 1990). Various other manifestations include: (i) Large normalized cyclic hardening $\left((\Delta \sigma / 2)_{\max } /(\Delta \sigma / 2)_{1}\right)$, where $(\Delta \sigma / 2)_{1}$ is the first cycle tensile stress amplitude and $(\Delta \sigma / 2)_{\max }$ is the maximum tensile stress amplitude, and the ratio increases with decreasing strain rate. (ii) An

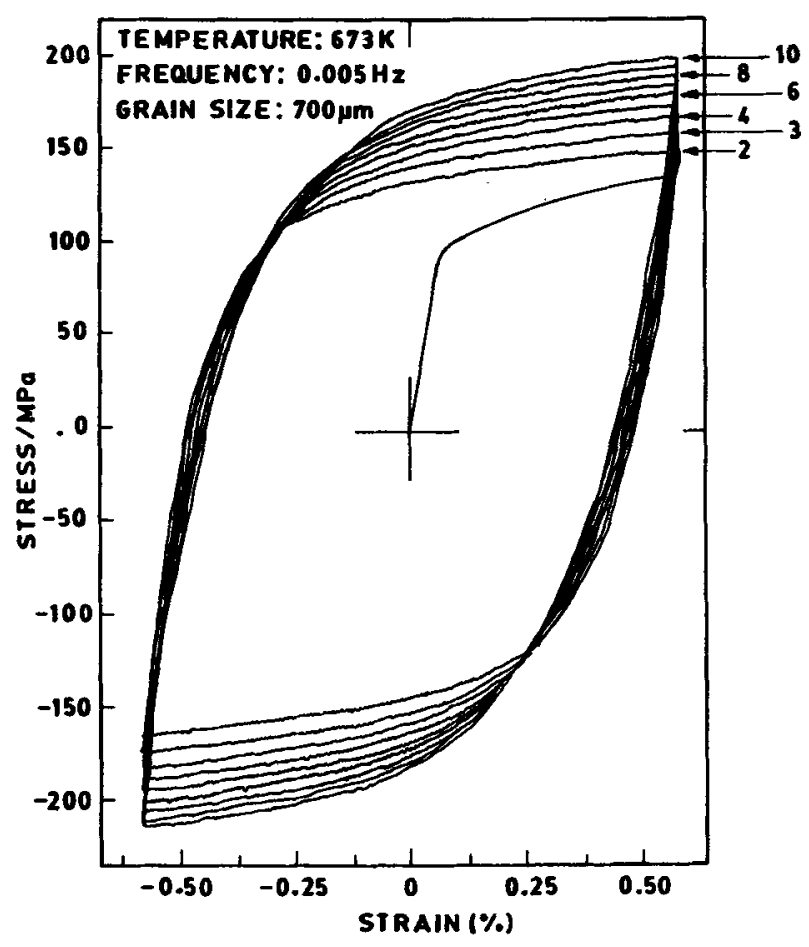

Figure 5. Stress-strain hysteresis loops exhibiting serrated flow in LCF test conducted at $673 \mathrm{~K}$ (grain size: $700 \mu \mathrm{m}$, strain range: $1.2 \%$, frequency: $0.005 \mathrm{~Hz}$ ). 
increase in the number of cycles to attain $(\Delta \sigma / 2)_{\max }$ with decreasing $\dot{\varepsilon}$. (iii) For a given total strain range, plastic strain range decreases with increasing temperature or decreasing strain rate. (iv) Increase in stress response with decreasing strain rate (negative strain rate sensitivity) or increasing temperature.

Some examples from our work are presented to illustrate the above-mentioned features: Figure 6 shows the influence of strain rate on normalized cyclic hardening curves for a type 304 stainless steel with a grain size of $310 \mu \mathrm{m}$ (Bhanu Sankara Rao et al 1990). It is clearly seen from this figure that decreasing strain rate from $1.6 \times 10^{-2} \mathrm{~s}^{-1}$ to $1.6 \times 10^{-4} \mathrm{~s}^{-1}$ resulted in an increase in the normalized cyclic hardening and also an increase in the number of cycles to attain $(\Delta \sigma / 2)_{\max }$. An extended period of nearly stable stress response after the initial cyclic hardening is observed only in the case of higher $\dot{\varepsilon}\left(1.6 \times 10^{-2} \mathrm{~s}^{-1}\right)$ at which no other effects of DSA were seen. At lower strain rates where DSA was manifested, the period of strain hardening dominated the stress response. Table 1 summarizes the influence of $\dot{\varepsilon}$ on LCF properties of type $304 \mathrm{SS}(310 \mu \mathrm{m}$ grain size) when fatigue tested at $823 \mathrm{~K}$ with a total strain range

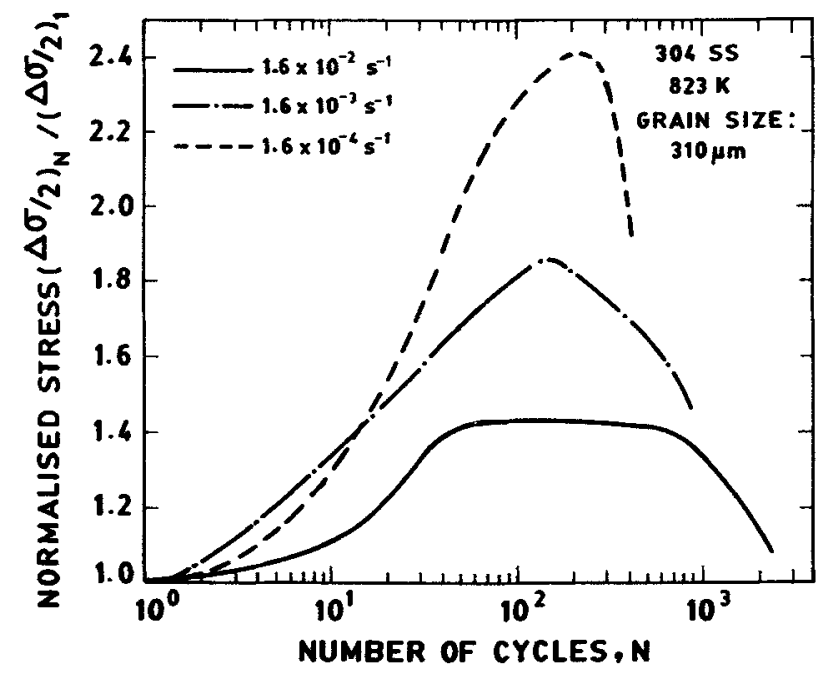

Figure 6. Normalized cyclic hardening curves illustrating the influence of strain rate at $823 \mathrm{~K}$ for type 304 stainless steel with medium grain size $(310 \mu \mathrm{m})$. Strain amplitude $= \pm 0.4 \%$.

Table 1. Low cycle fatigue properties of type 304 stainless steel as a function of strain rate at $823 \mathrm{~K}\left(\Delta \varepsilon_{t}=0.80 \%, \mathrm{GS}=310 \mu \mathrm{m}\right)$.

\begin{tabular}{|c|c|c|c|c|c|c|c|}
\hline $\begin{array}{l}\dot{\varepsilon} \\
\left(s^{-1}\right)\end{array}$ & $\begin{array}{l}\Delta \varepsilon_{p} \\
(\%)\end{array}$ & $\begin{array}{c}(\Delta \sigma / 2)_{1} \\
(\mathrm{MPa})\end{array}$ & $\begin{array}{c}(\Delta \sigma / 2)_{\max } \\
(\mathrm{MPa})\end{array}$ & $N_{i}$ & $N_{p}$ & $N_{f}$ & Remarks \\
\hline $1.6 \times 10^{-2}$ & 0.567 & 159 & 227 & 600 & 1790 & 2390 & 0 \\
\hline $1.6 \times 10^{-3}$ & 0.562 & 147 & 262 & 160 & 555 & 715 & - \\
\hline $1.6 \times 10^{-4}$ & 0.555 & 112 & 271 & 220 & 209 & 429 & $x$ \\
\hline
\end{tabular}




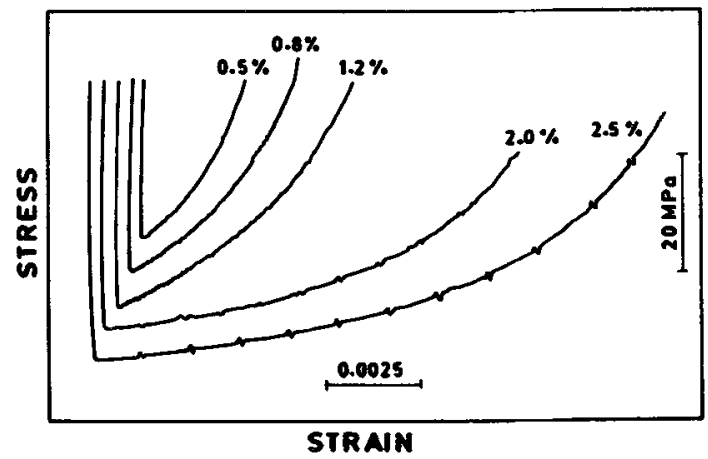

Figure 7. Stress-strain hysteresis loops in the compression portion indicating serrated flow at different total strain ranges (type 304 SS, GS: $310 \mu \mathrm{m}$, temperature: $823 \mathrm{~K}$, frequency: $0-01 \mathrm{~Hz}$.

of $0.80 \%$. The following observations could be made from the table: (i) fatigue life $\left(N_{f}\right)$ decreases with decreasing $\dot{\varepsilon}$, (ii) plastic strain range $\left(\Delta \varepsilon_{p}\right)$ decreases with decreasing $\dot{\varepsilon}$, and (iii) with decreasing $\dot{\varepsilon}$, the first cycle stress amplitude $(\Delta \sigma / 2)_{1}$ is found to decrease, but strain hardening dramatically increases to cause a steep rise in the maximum stress amplitude $(\Delta \sigma / 2)_{\max }$.

In addition, markedly unstable plastic flow (serrations) has been noted in the plastic regions of stress-strain hysteresis loops at the lowest strain rate employed. The serrated flow observed in the lower $\dot{\varepsilon}$ at $823 \mathrm{~K}$ could be ascertained from the compiled diagram (figure 7) depicting the strain range dependence of serrated flow. Results presented in table 1 and figure 6 clearly indicate that there was an increase in cyclic stress when $\dot{\varepsilon}$ was decreased from $1.6 \times 10^{-2} \mathrm{~s}^{-1}$ to $1.6 \times 10^{-3} \mathrm{~s}^{-1}$. However, stress-strain hysteresis loops remained smooth at $\dot{\varepsilon}=1.6 \times 10^{-3} \mathrm{~s}^{-1}$. From these results it is clear that DSA commenced earlier than it is manifested in the form of serrations in hysteresis curves.

A comparison of the results of LCF with tensile deformation (Bhanu Sankara Rao et al 1990) indicated that serrated flow occurred over a wider temperature range in LCF than in monotonic deformation. Particularly, the temperature at which serrations first appeared was lower in LCF. It is suggested that cyclic deformation enables the serrated flow to occur at lower temperatures because of the enhanced diffusion of solute atoms with the aid of non-equilibrium vacancies generated during fatigue deformation. Reverse straining creates vacancies at a rate greater than unidirectional deformation (Johnson and Johnson 1965; Bhanu Sankara Rao et al 1986a). Excess vacancies have also been suggested to aid uniform cavitation during fatigue testing (Bhanu Sankara Rao et al 1986d, 1989).

Strain rate effects on high temperature low cycle fatigue properties of a Nimonic PE16 superalloy have been recently evaluated in the temperature range 523-923 K (Valsan et al 1993). LCF tests were performed at a total strain amplitude of $\pm 0.6 \%$ on samples possessing two different prior microstructures: microstructure A (solutionannealed condition; free of $\gamma^{\prime}$ and carbides) and microstructure $B$ (double-aged condition; $18 \mathrm{~nm}$ dia $\gamma^{\prime}+\mathbf{M}_{23} \mathrm{C}_{6}$ carbides). In microstructure $A$, at lower temperatures (below $723 \mathrm{~K}$ ) DSA was manifested in the form of type A+B serrations (figure 8a), while type $C$ serrations were seen at $T>723 \mathrm{~K}$ (figure $8 \mathrm{~b}$ ). Variation of peak tensile 
stress with temperature exhibited peaks/plateau similar to observations in tensile deformation in DSA regime.

Nitrogen-alloyed type $316 \mathrm{~L}$ (known as $316 \mathrm{LN}$ ) is currently a favoured structural material for most of the components of LMFBRs. Improved fatigue resistance of this stainless steel has been attributed to retardation of the crack initiation phase due to the increased planarity of slip (Douglas et al 1964; Nilsson 1984; Vogt et al 1984). Investigations have been undertaken to understand the effects of temperature on LCF properties of 316LN in the temperature range 298-873 K (Srinivasan et al 1991). LCF tests were conducted at a strain rate of $3 \times 10^{-3} \mathrm{~s}^{-1}$ with a total strain amplitude of $\pm 0.60 \%$, and the results are presented in table 2 . Important manifestations of the occurrence of DSA like pronounced cyclic hardening, increase in response stress with increase in temperature and decrease in plastic strain range with increasing temperature could be discerned from these results. Room temperature results are influenced due to formation of deformation-induced martensite. A quantitative analysis of stressstrain hysteresis loops corresponding to the cycle displaying maximum stress amplitude at all temperatures has been carried out in order to obtain friction stress (thermal) and back stress (athermal) according to the scheme described by Cottrell (1959) (figure 9). The increase in total stress amplitude with temperature is mainly due to

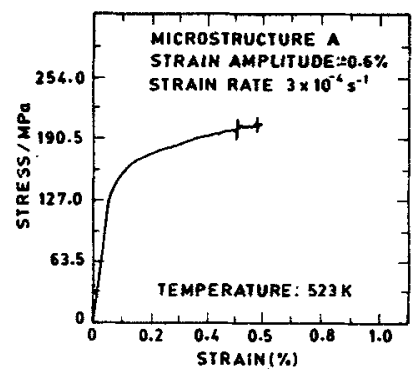

(a)

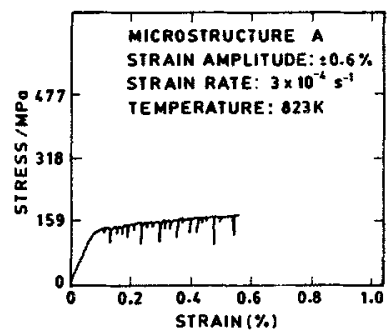

(b)

Figure 8. Serrations observed in Nimonic PE16 superalloy (microstructure A) (a) at $523 \mathrm{~K}$ (type $\mathrm{A}+\mathrm{B}$ serrations) and (b) at $823 \mathrm{~K}$ (type $\mathrm{C}$ serrations); (strain amplitude $= \pm 0-60 \%$, strain rate $=3 \times 10^{-4} s^{-1}$ ).

Table 2. Effects of temperature on LCF properties of type $316 \mathrm{LN}$ stainless steel $\left(\Delta \varepsilon_{t} / 2= \pm 0.60 \%\right)$.

\begin{tabular}{|c|c|c|c|c|c|c|c|}
\hline \multirow[b]{2}{*}{$\begin{array}{l}\text { Temperature } \\
\text { (K) }\end{array}$} & \multirow[b]{2}{*}{$\begin{array}{c}\Delta \varepsilon_{p} / 2 \\
(\%)\end{array}$} & \multicolumn{3}{|c|}{ Cyclic stress amplitude (MPa) } & \multicolumn{2}{|c|}{ Number of cycles to } & \multirow{2}{*}{$\begin{array}{l}\text { Peak stress } \\
\text { first cycle } \\
\text { stress }\end{array}$} \\
\hline & & $\begin{array}{l}\text { First } \\
\text { cycle }\end{array}$ & $\begin{array}{l}\text { Half- } \\
\text { life }\end{array}$ & $\begin{array}{l}\text { Peak } \\
\text { stress }\end{array}$ & $\begin{array}{c}\text { Failure } \\
\left(N_{f}\right)\end{array}$ & $\begin{array}{c}\text { Separation } \\
\left(N_{\text {sep }}\right)\end{array}$ & \\
\hline 298 & 0.45 & 298 & 334 & 350 & 2850 & 3090 & $1 \cdot 17$ \\
\hline 573 & 0.45 & 168 & 258 & 287 & 3740 & 3900 & 1.71 \\
\hline 673 & 0.42 & 151 & 286 & 306 & 1991 & 2110 & 2.03 \\
\hline 773 & 0.41 & 156 & 340 & 342 & 1150 & 1250 & $2 \cdot 19$ \\
\hline 823 & 0.39 & 158 & 334 & 346 & 650 & 725 & $2 \cdot 19$ \\
\hline 873 & 0.38 & 162 & 328 & 354 & 520 & 580 & $2 \cdot 19$ \\
\hline
\end{tabular}




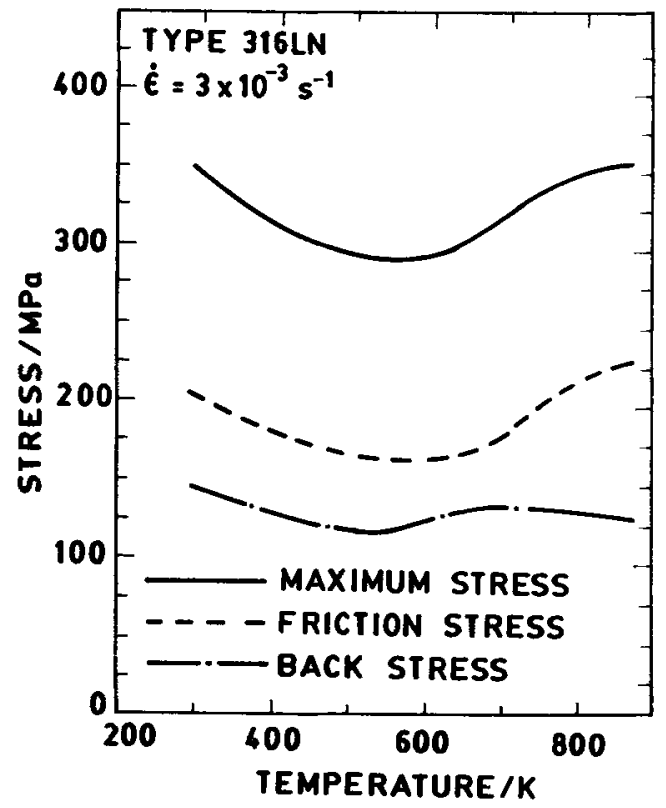

Figure 9. Variation of maximum, friction and back stresses with temperature for type 316LNSS.

the increase in friction stress from 573 to $873 \mathrm{~K}$. The enhanced locking of mobile dislocations by the solutes has been suggested to be the cause for the increase in friction stress with increasing temperature (Srinivasan et al 1991).

\subsection{Influence of DSA on LCF deformation and fracture}

Dynamic strain ageing exerts a significant effect on the fatigue behaviour of the material. The cyclic deformation mode, fracture behaviour and consequently the fatigue life get influenced by DSA. Occurrence of DSA has been found to enhance the degree of planarity of slip (Kanazawa et al 1985). The formation of cells and subgrains is retarded due to locking of dislocations by solute interaction which inhibits cross-slip and climb.

The influence of DSA on development of dislocation substructure during LCF deformation of austenitic stainless steel over wide range of test conditions has been examined by the author and his colleagues (Bhanu Sankara Rao et al 1990; Srinivasan et al 1991). In $316 \mathrm{LN}$, deformation substructure varied widely depending on test temperature (Srinivasan et al 1991). Cyclic deformation at $298 \mathrm{~K}$ led to the formation of crude cells with irregularly arranged dislocations in cell walls (figure 10), whereas at $573 \mathrm{~K}$, the majority of the grains consisted of a well-developed cell structure with interior regions of cells remaining free from dislocations (figure 11). At still higher test temperatures of $673 \mathrm{~K}$ and $773 \mathrm{~K}$ the substructure primarily consisted of homogeneously distributed dislocations, dislocation dipoles and dislocation loops (figure 12). As the temperature is increased from 573 to $873 \mathrm{~K}$, the propensity for cell formation decreased and well-developed planar slip bands with pile-up of dislocations formed 


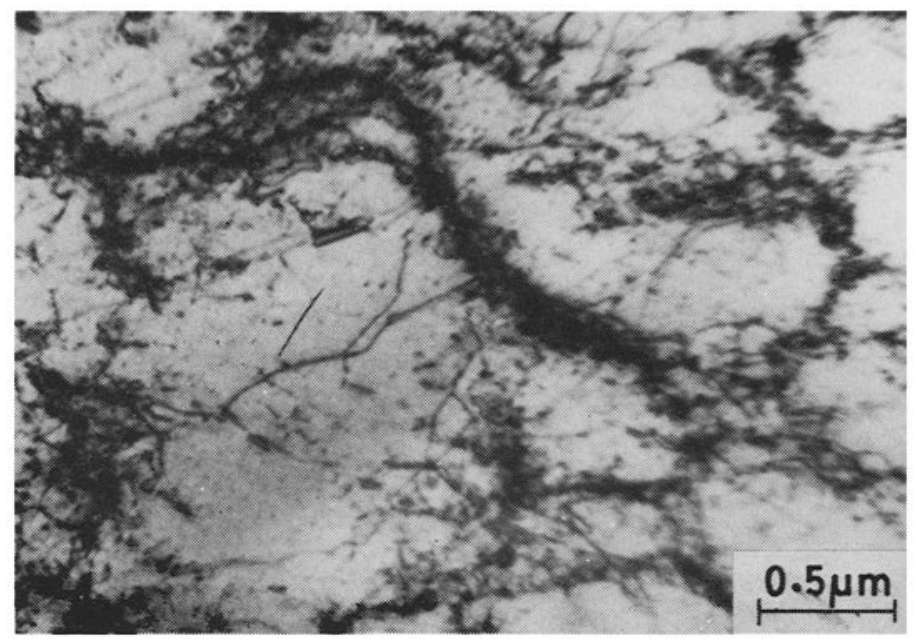

Figure 10. Development of crude cells with randomly arranged dislocations in cell walls at $298 \mathrm{~K}$ for type $316 \mathrm{LNSS}$.

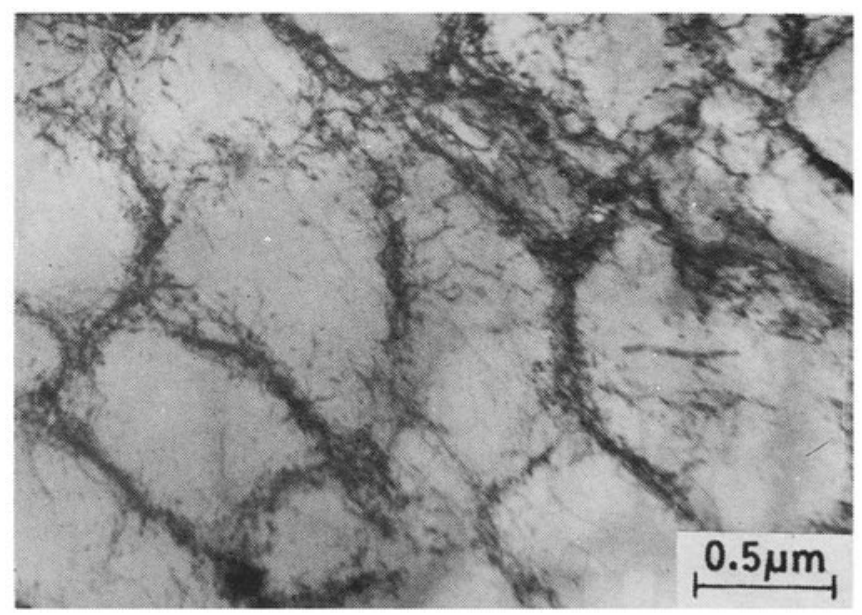

Figure 11. Well-developed cell structure at $573 \mathrm{~K}$ with relatively few dislocations in the interior regions of the cells in type $316 \mathrm{LNSS}$.

at $873 \mathrm{~K}$ (figure 13). The transition from cells to homogeneous dislocation distribution in the temperature range $573 \mathrm{~K}-873 \mathrm{~K}$ was found to correlate well with the reduction in $N_{f}$, enhanced initial cyclic hardening, a reduction in plastic-strain amplitude (table 2) and increase in the friction stress with increasing temperature (figure 9). These features are clear manifestations of DSA as discussed earlier and so the observed variation in dislocation substructure could be directly correlated with the occurrence of DSA.

The effects of strain rate in the range $1.6 \times 10^{-2}$ to $1.6 \times 10^{-4} \mathrm{~s}^{-1}$ on LCF deformation and fracture have been evaluated on type 304 SS at $823 \mathrm{~K}$ (Bhanu Sankara 


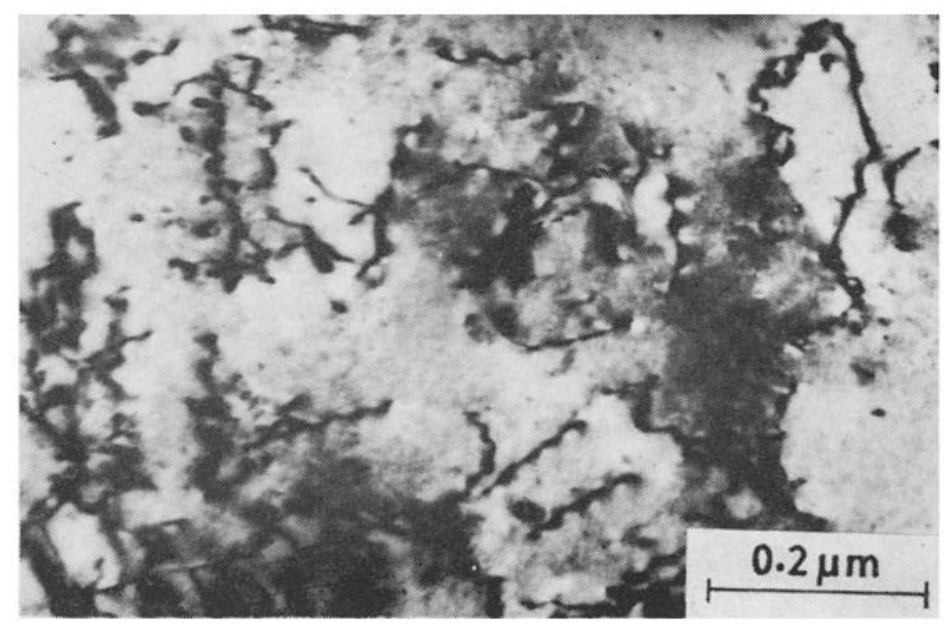

Figure 12 Planar dislocations and dislocation loops formed in fatigue tested samples at $773 \mathrm{~K}$ in type 316LNSS.

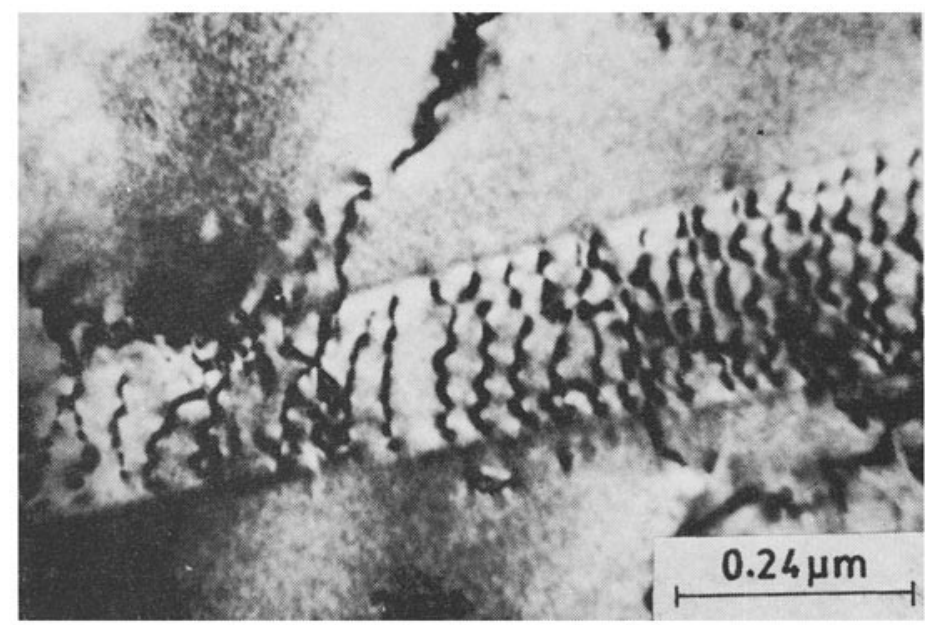

Figure 13. Well-developed planar slip bands with pile-up of dislocations at $873 \mathrm{~K}$ in 316LNSS.

Rao et al 1986c, 1990). TEM studies revealed that deformation occurred by planar slip at all the strain rates. However, the density of planar slip bands increased with decreasing $\dot{\varepsilon}$. Figure 14 shows a typical example of intense planar slip bands developed at $\dot{\varepsilon}=1.6 \times 10^{-4} \mathrm{~s}^{-1}$. An important additional feature in this figure is that the regions between the slip bands contained uniform distribution of dislocations. It has been suggested that DSA during tensile as well as cyclic deformation results from locking of mobile dislocations by substitutional solute atoms. The dislocation velocities maintained within the intense slip bands may be too high for solute-dislocation interactions to occur, hence it is proposed,that DSA in LCF would result from the solute locking of the slow moving dislocations between the slip bands (Bhanu Sankara 
Rao et al 1990). The differential movement of dislocations within and between slip bands would create deformation inhomogeneity.

That DSA strongly influences deformation during LCF has been brought out clearly in a recent study of the effects of strain rate on LCF behaviour of a Nimonic PE16 superalloy (Valsan et al 1993). In this study slip band spacings (i) were measured on the longitudinal sections of fatigue-tested specimens. Slip band spacing reflects the degree of homogeneity of deformation. Since slip bands represent the regions where strain is localized, the average spacing determines the extent of homogeneity of slip process in the matrix; greater the value of $i$, more inhomogeneous the deformation. The variation of $i$ with strain rate for the microstructure $\mathrm{A}$ is shown in figure 15. It is seen that $i$ decreases with increase in strain rate and exhibits a minimum at a strain rate of $3 \times 10^{-3} \mathrm{~s}^{-1}$. With further increase in strain rate, slip bands become more widely spaced. The value of $i$ is also found to increase with temperature at all strain rates. At the highest strain rate, there is close parallel between decrease in fatigue resistance and increase in degree of inhomogeneity of fatigue deformation.

DSA enhances the degree of inhomogeneity of deformation and partitions cyclic strain into separate regions marked by high and low amplitudes of dislocation motion, leading to strain localization in planar slip bands. Therefore, with widely spaced slip

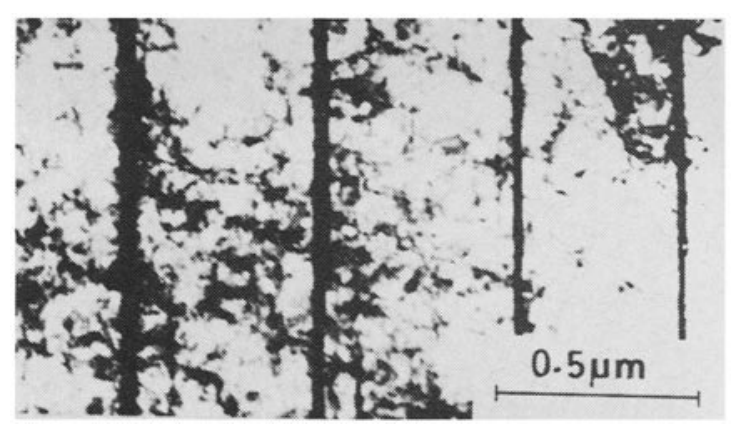

Figure 14. Slip bands and uniform distribution of dislocations in the interband regions (type 304 SS, GS: $310 \mu \mathrm{m}, \dot{\varepsilon}=1.6 \times 10^{-4} \mathrm{~s}^{-1}$ ).

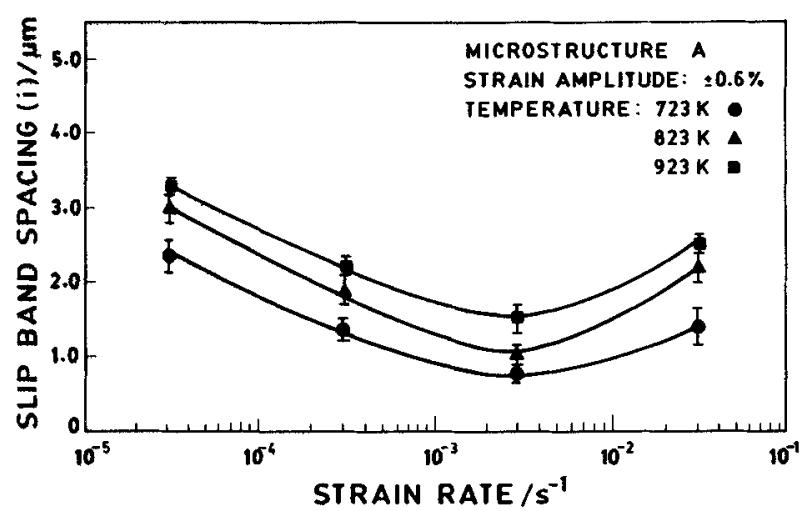

Figure 15. Variation of average slip band spacing $i$ with strain rate in alloy PE16 (microstructure A). 

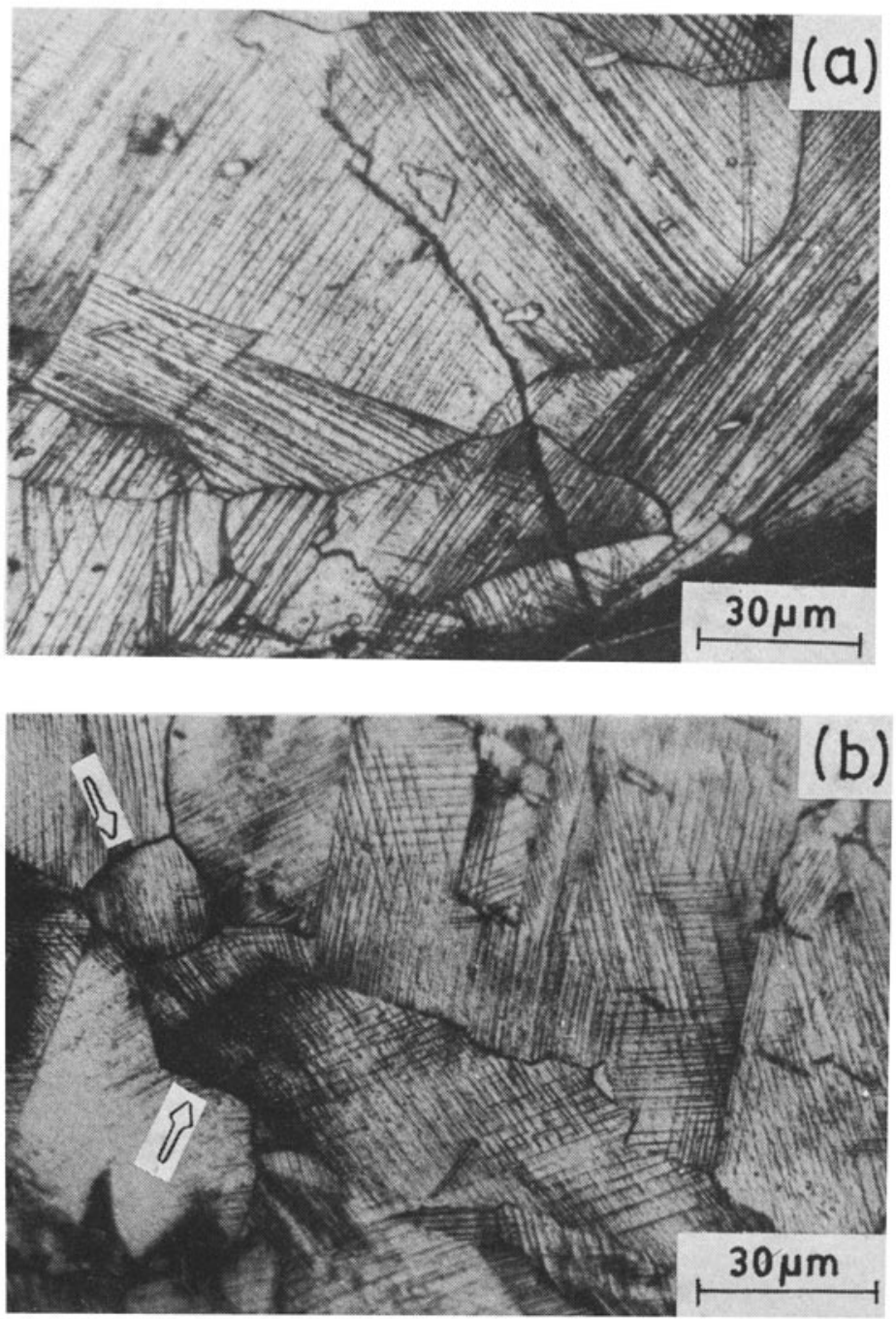

Figure 16. Fractographic observations in Nimonic PE16 (microstructure A), $\dot{\varepsilon}=3 \times 10^{-5} s^{-1}$, temperature $=723 \mathrm{~K}$ : (a) transgranular initiation and (b) internal grain boundary cracks associated with impingement of slip bands.

bands, the extent of strain localization increases and subsequently impingement of these slip bands causes internal grain boundary cracks (figure 16) and reduced fatigue life in the DSA regime at lower strain rates (figure 17). Grain boundary cracks due to impingement of slip bands were observed also in microstructure B which contains carbides at grain boundaries.

Because of the increased inhomogeneity of deformation under conditions which promote DSA during LCF, fracture mode and fatigue life have been found to be influenced significantly. The intersection of planar slip bands with the grain boundaries is found to cause internal grain boundary cracks in microstructure A in alloy PE16 (figure 16) and reduced life. Further, strain localization effects and number density 


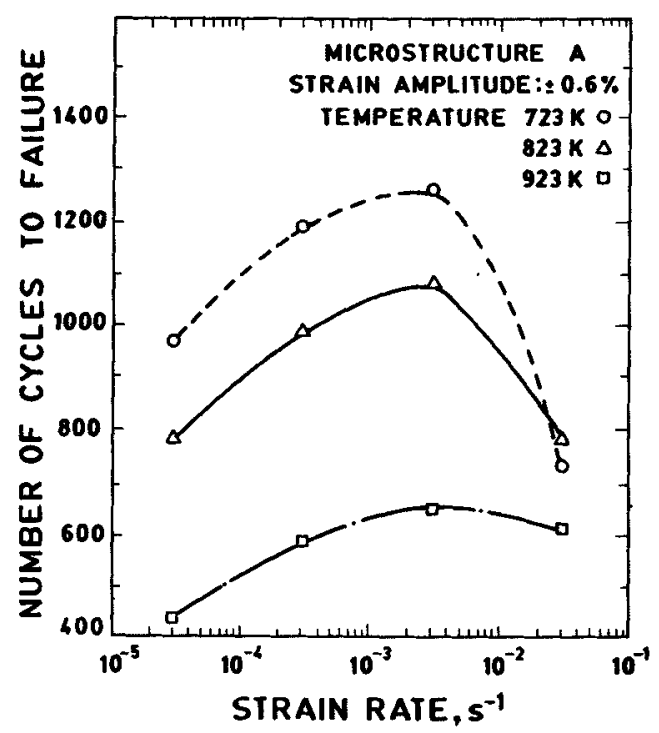

Figure 17. Variation of fatigue life with strain rate in alloy PE16 (microstructure A).

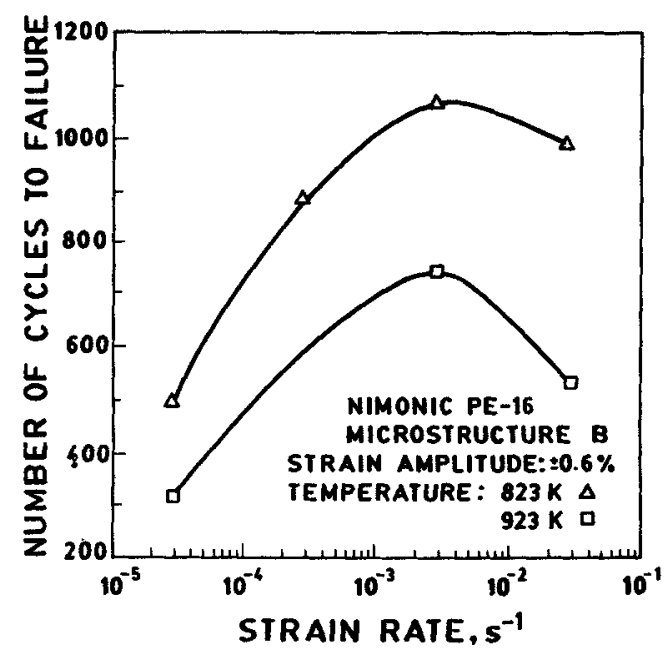

Figure 18. Variation of fatigue life with strain rate in alloy PE16 (microstructure B).

of internal grain boundary cracks in microstructure $\dot{B}$ in DSA regime are larger compared to microstructure $A$. In microstructure $B$, precipitates of $M_{23} C_{6}$ are present at the grain boundaries and impingement of planar slip bands causes decohesion of matrix-carbide interface leading to intergranular cracks. Lower fatigue life in microstructure B of PE16 in DSA regime (figure 18) is therefore attributed to the enhanced crack propagation rate assisted by increased internal grain boundary cracks.

SEM studies on type 304 SS (Bhanu Sankara Rao et al 1990) revealed that at the two higher strain rates $\left(1.6 \times 10^{-3} \mathrm{~s}^{-1}\right.$ and $\left.1.6 \times 10^{-2} \mathrm{~s}^{-1}\right)$ the fatigue crack propagated transgranularly by ductile striation mechanism, and by a mixed transgranular and 

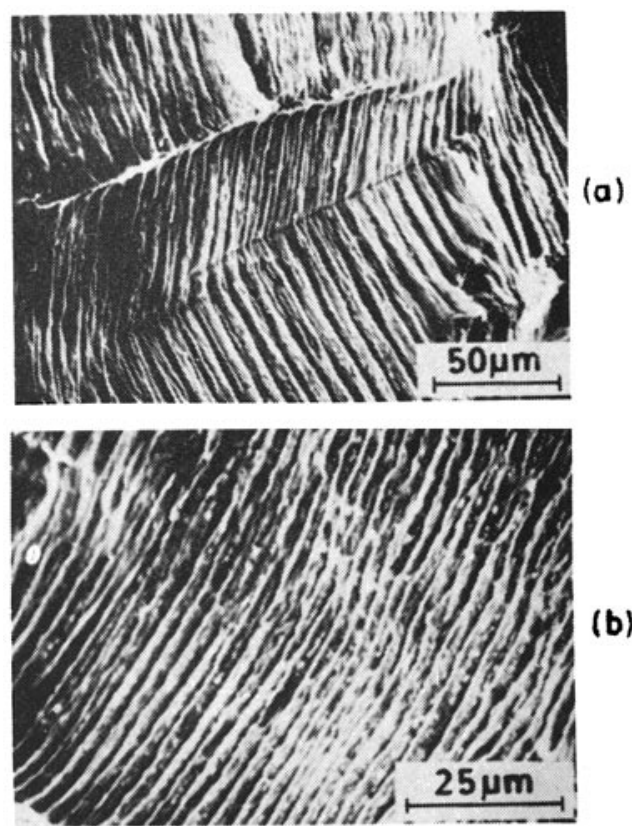

(b)

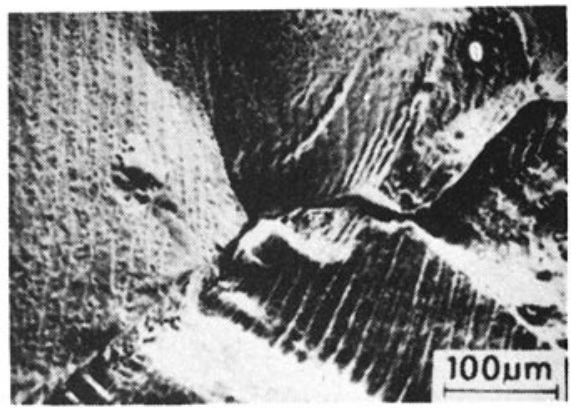

(c)

Figure 19. Crack propagation modes as a function of strain rate at $823 \mathrm{~K}$ in medium grained $(310 \mu \mathrm{m})$ type $304 \mathrm{SS}$; (a) transgranular stage II propagation $\left(\dot{\varepsilon}=1.6 \times 10^{-2} \mathrm{~s}^{-1}\right)$, (b) transgranular stage II propagation $\left(\dot{\varepsilon}=1.6 \times 10^{-3} \mathrm{~s}^{-1}\right)$ and (c) mixed mode propagation $\left(\dot{\varepsilon}=1.6 \times 10^{-4} \mathrm{~s}^{-1}\right)$.

intergranular mode at the lowest $\dot{\varepsilon}=1.6 \times 10^{-4} \mathrm{~s}^{-1}$ (figure 19). It should be noted that the occurrence of serrated flow coincided with the development of intergranular cracking. Also, where negative strain rate sensitivity existed but no serrated flow occurred, crack propagation remained transgranular. Intergranular decohesion at $\dot{\varepsilon}=1.6 \times 10^{-4} \mathrm{~s}^{-1}$ (figure 19c) was caused by the impingement of slip bands on grain boundaries.

Conditions which lead to intergranular cracking by impingement of slip bands during fatigue of polycrystalline copper have been analysed theoretically and experimentally by Mughrabi et al (1983). It has been suggested that the intergranular decohesion due to intersection of slip bands results from the long-range stresses associated with the piling up of dislocations. According to Stroh (1957), the largest tensile stress at the head of a pile-up occurs along a plane making an angle of $70.5^{\circ}$ 
with the pile-up. Mughrabi et al (1983) considered that in real situations these planes lie almost in the grain boundary itself.

\subsection{DSA effects on LCF life}

As discussed above, the occurrence of DSA leads to slip inhomogeneity and increased incidence of grain boundary cracking. These processes would enhance crack initiation as well as crack propagation during LCF and degrade life. Further the higher response stresses developed during strain-controlled cyclic deformation in LCF can lead to a large stress concentration at the crack tip, which would account for increased crack growth rates and hence a reduced number of cycles in the crack propagation stage (Bhanu Sankara Rao 1989). Moreover, higher response stresses would act to reduce the critical crack size for final fracture (Bressers and Verhegghee 1981) reducing the number of cycles to failure. A correlation between the variation of life with strain rate and slip band spacing with strain rate further supports the view that DSA degrades life by localising flow (figures 15 and 17). The decrease in fatigue life with strain rate (table 1) and fractographic observation (figure 19) further bring out the deleterious effect of DSA on LCF life.

\subsection{Effects of grain size on DSA during LCF}

The influence of DSA on LCF properties is dependent on microstructural features such as second phase particles as revealed in the study of LCF of various microstructures in alloy PE16 (Valsan et al 1993). Grain size is another microstructural parameter which determines the influence of DSA on fatigue behaviour. Grain size has been shown to influence the phenomenon of DSA during LCF in an austenitic stainless steel (Bhanu Sankara Rao et al 1991). Type of serrations and the critical strain for the onset of serrations are known to vary with prior grain size. In fact, it is suggested that grain boundary regions would be the preferred sites for the occurrence of DSA in monotonic deformation (Mannan et al 1983). Treatments that lead to variation in grain boundary microstructure (like thermal ageing) also influence DSA (Samuel et al 1988). Strain-controlled LCF tests have been conducted on type 304 stainless steel for various grain sizes at $823 \mathrm{~K}$ by employing strain ranges from $0.50 \%$ to $1.2 \%$ and cyclic frequencies in the range $0.001 \mathrm{~Hz}$ to $1.0 \mathrm{~Hz}$ (Bhanu Sankara Rao et al 1991). Grain sizes (GS) considered in this study were 75, 310 and $700 \mu \mathrm{m}$. The results of this study are summarized in table 3 . The common observations for all grain sizes which establish the occurrence of DSA during LCF are: reduction in fatigue life $\left(N_{f}\right)$, increase in maximum stress amplitude, and a decrease in plastic strain range with decreasing strain rate. Further, an enhanced tendency for grain boundary decohesion with reduction in strain rate was also noticed. $N_{f}$ decreased markedly with decreasing $\dot{\varepsilon}$ in the case of medium $(310 \mu \mathrm{m})$ and coarse $(700 \mu \mathrm{m})$ grain sizes. Lowest $N_{f}$ was recorded for medium GS compared to other grain sizes at the two lower strain rates. All the grain sizes displayed serrations in stress-strain hysteresis loops at the lowest $\dot{\varepsilon}$ employed.

A summary of the tensile stress response from the hysteresis loops recorded for different strain rates is shown in figures 6 and 20 for medium and fine grain sizes respectively. Coarse GS exhibited a stress response similar to medium GS at all the 
Table 3. Low cycle fatigue properties of type $304 \mathrm{SS}$ as a function of grain size and $\dot{\varepsilon}$ at $823 \mathrm{~K}\left(\Delta \varepsilon_{\mathrm{t}}=0.80 \%\right)$.

\begin{tabular}{lcccccc}
\hline $\begin{array}{l}\text { Grain size } \\
(\mu \mathrm{m})\end{array}$ & $\begin{array}{c}\dot{\varepsilon} \\
\left(\mathrm{s}^{-1}\right)\end{array}$ & $\begin{array}{c}\Delta \varepsilon_{p} \\
(\%)\end{array}$ & $\begin{array}{c}(\Delta \sigma / 2)_{1} \\
(\mathrm{MPa})\end{array}$ & $\begin{array}{c}(\Delta \sigma / 2)_{\max } \\
(\mathrm{MPa})\end{array}$ & $N_{f}$ & Remarks \\
\hline 75 & $1.6 \times 10^{-2}$ & 0.569 & 183 & 238 & 1069 & $@$ \\
75 & $1.6 \times 10^{-3}$ & 0.480 & 159 & 271 & 1290 & $*$ \\
75 & $1.6 \times 10^{-4}$ & 0.424 & 138 & 279 & 796 & + \\
310 & $1.6 \times 10^{-2}$ & 0.567 & 159 & 227 & 2390 & $@$ \\
310 & $1.6 \times 10^{-3}$ & 0.562 & 147 & 262 & 715 & $*$ \\
310 & $1.6 \times 10^{-4}$ & 0.555 & 112 & 271 & 429 & + \\
700 & $1.6 \times 10^{-2}$ & 0.500 & 113 & 232 & 3000 & $\vdots$ \\
700 & $1.6 \times 10^{-3}$ & 0.412 & 102 & 255 & 1275 & $*$ \\
700 & $1.6 \times 10^{-4}$ & 0.368 & 108 & 278 & 875 & + \\
\hline
\end{tabular}

(a smooth stress-strain hysteresis loops; * smooth stress-strain hysteresis loops + dynamic strain ageing; + serrated flow in the plastic regions of stress-strain hysteresis loops.

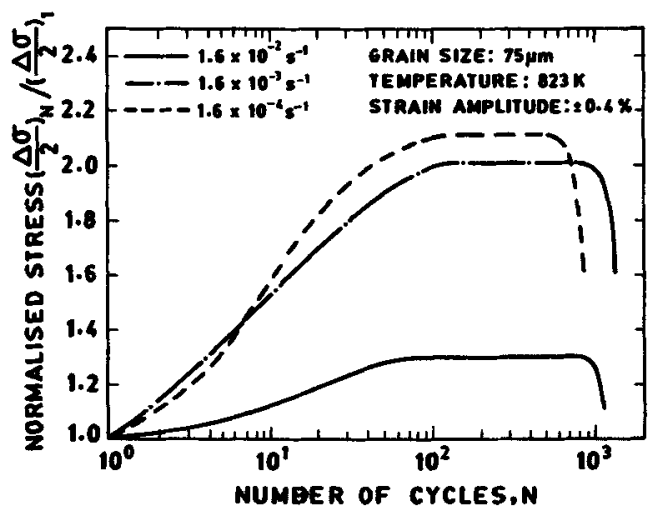

Figure 20. Normalized stress response plots as a function of strain rate in fine grained $(75 \mu \mathrm{m})$ type $304 \mathrm{SS}$ at $823 \mathrm{~K}$.

strain rates. It is observed from these figures that fine GS exhibited a period of strain hardening followed by an extended period of a nearly saturation stress response at all the strain rates, while medium and coarse grain sizes showed this behaviour only at higher $\dot{\varepsilon}$.

TEM observations of dislocation substructures clearly revealed that the deformation mechanisms depend on GS and $\dot{\varepsilon}$. The substructure in fine GS at higher $\dot{\varepsilon}$ was characterized by randomly distributed dislocations (figure 21). On decreasing the strain rate from $1.6 \times 10^{-2} \mathrm{~s}^{-1}$ to $1.6 \times 10^{-4} \mathrm{~s}^{-1}$, an increase in dislocation density was observed (Bhanu Sankara Rao et al 1991). Planar slip bands were more well developed in medium and coarse grain sizes at all the strain rates compared to fine GS. The regions between the slip bands in medium and coarse grain sizes contained randomly distributed dislocations and dislocation tangles (figure 14). With decrease in strain rate the density of slip bands was found to increase. 


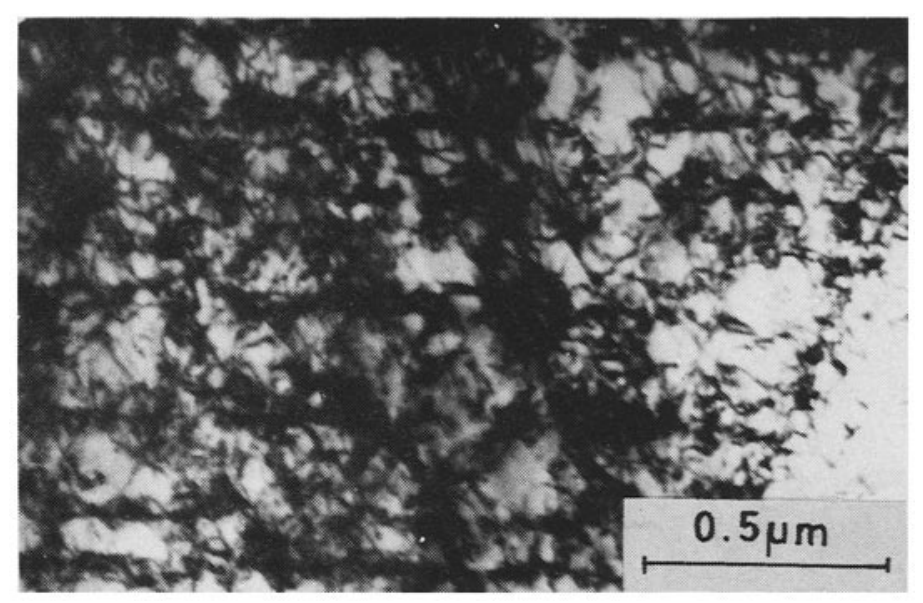

Figure 21. Dislocation substructure in fine-grained ( $75 \mu \mathrm{m})$ type $304 \mathrm{SS}$ at $823 \mathrm{~K}(\dot{\varepsilon}=1.6 \times$ $10^{-2} s^{-1}$ ).

It is well known that in polycrystals multiple slip systems operate in the immediate vicinity of grain boundaries in order to preserve the cohesion of grain boundaries (Calnan and Clews 1951). Consequently, finer the grain size, more would be the grain volume experiencing multiple slip. This would explain why planar slip in fine GS was less intense even though DSA effects were seen to be more pronounced at lower strain rates in fine-grained material.

At high and medium strain rates, the fatigue crack propagated transgranularly by the ductile striation formation mechanism. Coincident with large reductions in $N_{f}$, at lower $\dot{\varepsilon}$, all the grain sizes displayed mixed (transgranular and intergranular) mode of fracture. However, the degree of intergranular cracking was dependent on the grain size. It is observed from figures 19 and 22 , that medium GS showed higher propensity for brittle decohesion of grain boundaries with decreasing $\dot{\varepsilon}$ when compared with fine GS. The extensive intergranular cracking in medium GS at low strain rate (figure 19c) has been attributed to the slip bands impingement at grain boundaries.

The higher fatigue resistance of fine-grained material compared to medium GS under DSA condition was found to have a correlation with the reduced incidence of intergranular cracking (figure 22c). Since the slip length cannot exceed the grain diameter, fine grain reduces the stress concentrations and associated intergranular cracking by reducing the number of dislocations in a pile-up. Furthermore, reduced tendency for planar slip observed in fine-grained material can be invoked to explain the reduced incidence of intergranular cracking and improved resistance to fatigue. Coarse GS has also shown higher resistance to fatigue than the medium GS under DSA conditions (table 3). Microscopic investigations showed that many of the slip bands do not run across the coarse grain and instead get terminated abruptly in the intragranular regions (Bhanu Sankara Rao et al 1991). This is primarily because slip lengths of greater magnitude are difficult to develop and sustain. Under such conditions the incidence of intergranular cracking decreased again. Further, the plastic strain developed in a cycle in coarse grained material was rather small (table 3 ), leading to a situation where a large number of cycles would be needed to exhaust the tensile ductility of the material. 


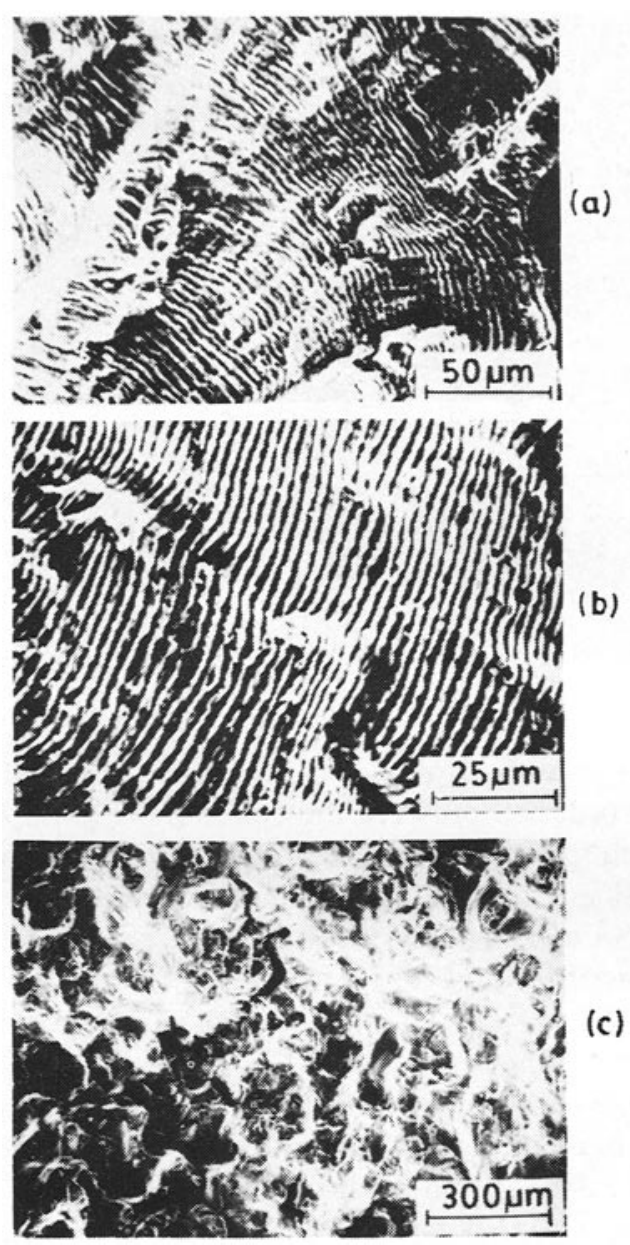

Figure 22. Crack propagation modes in fine grained $(75 \mu \mathrm{m})$ type $304 \mathrm{SS}$ at $823 \mathrm{~K}$ : (a) transgranular stage II propagation $\left(\dot{\varepsilon}=1.6 \times 10^{-2} \mathrm{~s}^{-1}\right)$; (b) transgranular stage II propagation $\left(\dot{\varepsilon}=1.6 \times 10^{-3} \mathrm{~s}^{-1}\right)$ and (c) mixed mode propagation $\left(\dot{\varepsilon}=1.6 \times 10^{-4} \mathrm{~s}^{-1}\right)$.

\section{Conclusions}

Studies conducted by the present author and his colleagues to assess the role played by DSA in LCF behaviour of austenitic stainless steels (type 304 SS and type 316LN SS) and a superalloy (Nimonic PE16) have been presented in this paper. Important observations can be summarized as follows:

(i) Manifestations of DSA during total strain-controlled LCF tests are serrations in stress-strain hysteresis loops, enhanced cyclic work hardening, reduced plastic strain range and increase in response stress with decreasing strain rate or increasing temperature.

(ii) DSA promotes localization of plastic flow leading to formation of intense slip bands. In type $304 \mathrm{SS}$, when fatigue tested at $823 \mathrm{~K}$, the deformation occurred by 
planar slip. With decreasing strain rate, the density of planar slip bands increased resulting in reduction in fatigue life.

(iii) In the case of PE16 alloy, under DSA regime the slip band spacing increased with decreasing strain rate leading to localization of deformation. This localization of flow led to reduction in LCF life.

(iv) Temperature dependence of LCF deformation in type $316 \mathrm{LN}$ stainless steel indicates that the propensity for cell formation increased from $298 \mathrm{~K}$ to $573 \mathrm{~K}$, whereas beyond $573 \mathrm{~K}$ (under DSA condition), cyclic deformation occurred by planar slip with well-defined slip bands at $873 \mathrm{~K}$ where DSA effects were prominent.

(v) Impingement of slip bands on grain boundaries leads to internal grain boundary cracks. Therefore, with decreasing strain rate, the failure mode changes from transgranular crack propagation to mixed (transgranular and intergranular) mode propagation as observed in the case of type $304 \mathrm{SS}$ at $823 \mathrm{~K}$. This leads to life reduction with decreasing strain rate.

(vi) The presence of grain boundary carbides (as in microstructure B of alloy PE16) resulted in enhanced internal grain boundary cracks due to impingement of slip bands causing decohesion of matrix-carbide interface. Consequently, microstructure $B$ exhibited lower fatigue life than microstructure A (solution-annealed) in the DSA regime.

(vii) Grain size has been shown to be an important factor determining the effects of DSA on LCF in type 304 SS. Slip bands were found to be well developed in medium grain size $(310 \mu \mathrm{m})$ than in fine grain size $(75 \mu \mathrm{m})$ material. This resulted in minimum fatigue life for medium grain size.

\section{Acknowledgements}

The author gratefully acknowledges the collaboration of Shri A Veeramani in the preparation of this paper. The work reported is the outcome of dedicated efforts of his various colleagues in the mechanical properties section. He is thankful to Dr Placid Rodriguez for guidance, encouragement and support at various stages of these investigations.

\section{References}

Bhanu Sankara Rao K 1989 Influence of metallurgical variables on low cycle fatigue behaviour of type 304 stainless steel, $\mathrm{Ph}$. D Thesis, University of Madras, Madras

Bhanu Sankara Rao K, Sandhya R and Mannan S L 1993 Int. J. Fatigue 15221

Bhanu Sankara Rao K, Seetharaman V, Mannan S L and Rodriguez P 1986a High Temp. Mater. Proc. 763

Bhanu Sankara Rao K, Valsan M, Sandhya R, Mannan S L and Rodriguez P 1986b Proc. Int. Conf. Creep, JSME, Tokyo 77

Bhanu Sankara Rao K, Valsan M, Sandhya R, Mannan S L and Rodriguez P 1986c High Temp. Mater. Proc. 7171

Bhanu Sankara Rao K, Vijayalakshmi M, Valsan M, Mannan S L and Rodriguez P 1986d Scr. Metall. 20989

Bhanu Sankara Rao K, Vijayalakshmi M, Valsan M, Mannan S L and Rodriguez P 1989 Scr. Metall. 23157

Bhanu Sankara Rao K, Valsan M, Sandhya R, Mannan S L and Rodriguez P 1990 Met. Mater. Proc. 217

Bhanu Sankara Rao K, Valsan M, Sandhya R, Mannan S L and Rodriguez P 1991 Trans. Indian Inst. Met. 44255 
Bressers J 1985 Proc. Int. Conf. on high temperature alloys: their exploitable potential (eds) J B Marriott et al (London: Elsevier Appl. Sci.) p. 385

Bressers $J$ and Verhegghee B 1981 Res. Mech. Lett. 155

Calnan E A and Clews C J B 1951 Philos. Mag. 42616

Choudhary B K, Bhanu Sankara Rao K and Mannan S L 1991 Mater. Sci. Eng. A148 267

Clavel M. Levailant C and Pineau A 1980 Proc. Conf. on creep-fatigue-environment interaction (eds) R M Pelloux and N S Stoloff (The Metall. Soc. of AIME) p. 24

Coffin L F $1971 J$. Mater. 6388

Collin L F 1972 Metall. Trans. 31777

Coffin L F 1974 Proc. Inst. Mech. Engrs. 186109

Coffin L. F 1977 Fracture 1977, ICF-4 (ed) D M R Taplin (New York: Pergamon Press) 1 p. 263

Cook R H and Skelton R P 1979 Int. Met. Rev. 19199

Cottrell A H 1953 Philos. Mag. 44829

Cottrell A H 1959 Dislocations and plastic flow in crystals (London: Oxford Univ. Press) p. 111

Douglas D L. Thomas G and Rosser W R 1964 Corrosion $2015 t$

Hayes R W and Hayes W C 1984 Acta Metall. 32259

Hirakawa K, Tokiwasa K and Toyama K 1978 J. Soc. Mater. Sci. Jpn 27948

Johnson E W and Johnson H H 1965 Trans. AIME 2331332

Kanazawa K 1978 Trans. Nat. Res. Inst. Met. 20321

Kanazawa K, Yamaguchi K and Nishijima S 1985 Conf. on low cycle fatigue: Directions for the future, Lake George.

Kanazawa K and Yoshida S 1974 Appl. Inst. Mech. Eng. 1 C226

Kubin L P and Estrin Y 1990 Acta Metall. 38697

Mannan S L 1981 Influence of grain size on flow and fracture in AISI type 316 stainless steel, Ph. D Thesis, Indian Institute of Science, Bangalore

Mannan S L, Samuel K G and Rodriguez P 1982 Proc. 6th Int. Conf. on strength of metals and alloys, ICSMA6 (Melbourne) p. 637

Mannan S L, Samuel K G and Rodriguez P 1983 Trans. Indian Inst. Met. 36313

McCormick P G 1972 Acta Metall. 20351

Mediratta S R, Ramaswamy V and Rama Rao P 1986 Scr. Metall. 20555

Mughrabi H, Wang R, Differt $\mathrm{K}$ and Essman U 1983 Fatigue mechanisms: Advances in quantitative measurement of physical damage, ASTM STP 811 (Philadelphia: ASTM) p. 5

Mulford R A and Kocks U F 1979 Acta Metall. 271125

Nilsson J O 1984 Fat. Eng. Mater. Struct. 755

Pineau A 1983 Fatigue at high temperatures (ed) R P Skelton (London: Applied Sci. Pub.) p. 305

Rodriguez P 1984 Bull. Mater. Sci. 6653

Samuel K G, Mannan S L and Rodriguez P 1988 Acta Metall. 362323

Sanders R E and Starke E A 1977 Mater. Sci. Eng. 2853

Sandhya R, Bhanu Sankara Rao K and Mannan S L 1989 Trans. Indian Inst. Met. 42 (Suppl.) S217

Sleeswyk A W 1958 Acta Metall. 6598

Solomon H D and Colfin L F 1973 Fatigue at elevated temperatures, ASTM STP 520, (Philadelphia: ASTM) p. 112

Srinivasan V S, Sandhya R, Bhanu Sankara Rao K, Mannan S L and Raghavan K S 1991 Int. J. Fatigue 13471

Stroh A N 1957 Adv. Phys. 6418

Valsan M, Bhanu Sankara Rao K and Mannan S L 1989 Trans. Indian Inst. Met. 42 (Suppl.) S203

Valsan M, Sastry D H, Bhanu Sankara Rao K and Mannan S L 1993 Metall. Trans. (to appear)

Van den Beukel A and Kocks U F 1982 Acta Metall. 301027

Venkadesan S, Venugopal S, Sivaprasad P V and Rodriguez P 1992 Mater. Trans. JIM 331040

Vogt J B, Degallaix S and Foct J 1984 Int. J. Fatigue 6211

Yamaguchi K, Kanazawa K and Yoshida S 1977 Mater. Sci. Eng. 11439 